\title{
Expanding data is critical to assessing gendered impacts of household energy use
}

\author{
Zeenah Haddad and colleagues call for an expansion of data on household energy use routinely \\ collected through national surveys to gauge the health effects by gender
}

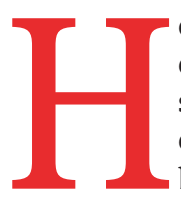

ousehold air pollution is caused when polluting fuels, such as wood, animal dung, charcoal, and kerosene, are burnt in inefficient devices for cooking, heating, and lighting. Exposure to household air pollution is a leading cause of premature death and disability in low and middle income countries, and contributes to many serious health conditions, including acute lower respiratory infection, chronic obstructive pulmonary disease, lung cancer, stroke, and cardiovascular disease. ${ }^{12}$ Additionally, pollution from burning such fuels indoors is not confined to the home, as carbon dioxide, black carbon, and other pollutants escape through windows, doors, and chimneys, contributing to outdoor air pollution and climate change. ${ }^{3}$ Global reliance on wood that has been harvested unsustainably for cooking and heating produces pollutants equivalent to around $2 \%$ of global carbon emissions. ${ }^{4}$

Women are especially harmed by inefficient use of household energy because cooking and collecting fuel are often considered the woman's domain. ${ }^{5}$

\section{REY RECOMMENDATIONS}

- Household air pollution threatens the health of billions and contributes to climate change

- Women and girls are disproportionately affected because they are often responsible for household energy related tasks

- Several existing national surveys have recently incorporated additional questions on household energy use, but considerable gaps remain, particularly related to assessing gendered health and livelihood impacts

- Governments should request that core questions on household energy use, recommended by experts, are included in national surveys to better characterise gendered impacts and inform investment and policy decisions
${ }^{6}$ Studies in Africa and Asia have found that women can spend between three and nearly six hours a day on activities related to cooking and collecting fuel. ${ }^{7}$ These tasks expose them to substantial concentrations of polluted fumes and place them at risk of injury while collecting heavy loads of fuel as well as attacks when collecting fuel in insecure locations. They also deprive them of time to pursue education, earn money, and engage in other growth opportunities. ${ }^{5}$

The disproportionate effect on women can be seen from the statistic that household air pollution is the fifth leading risk factor for morbidity among women in low and middle income countries, whereas it is ranked eighth among men. ${ }^{8}$ ${ }^{9}$ Sixty per cent of premature deaths from household air pollution occur in women and children. ${ }^{5}$

\section{Existing data on household energy use}

Evidence on the effects of household air pollution, especially on women and children, has been growing in the past few decades. ${ }^{1011}$ National scale data on the wide ranging effects of household energy use disaggregated by sex are scarce, however. The primary sources for data on household air pollution and progress toward use of clean household energy are routinely administered national surveys that monitor health and development, such as governmental censuses and surveys administered by international agencies (including Unicef's Multiple Indicator Cluster Surveys (MICS) ${ }^{12}$ and USAID's Demographic and Health Surveys (DHS) $)^{13}$ ). These surveys are crucial for informing country and global policy making and funding decisions.

Data collected through these surveys are used as proxies for estimating household air pollution emissions and exposures and, indirectly, the impact on climate and health. ${ }^{14}$ Before 2020, however, these international surveys asked only about the main fuel used for cooking and the cooking location (table 1). This is in stark contrast to other global health priorities such as malaria and HIV/AIDS, for which MICS and DHS include hundreds of questions. ${ }^{12} 13$

\section{Progress toward dealing with household air pollution}

The scale and gravity of household air pollution, especially for women, demand far greater attention. Recently, global efforts to scale up access to clean energy in households to protect health has increased. Global tracking and monitoring systems for household energy use now rely on the health based recommendations in World Health Organization guidelines to define which fuels and stoves used by households are considered clean. ${ }^{15} 16$ Global pacts, such as the 2030 sustainable development goals (SDGs), have accelerated improvements in access to clean cooking. ${ }^{17}$ SDG 7, for instance, focuses on ensuring access to affordable, reliable, sustainable, and modern energy for all, including electricity and clean fuels and technologies. As a result, the percentage of the global population relying primarily on clean fuels and technologies for cooking has increased from $57 \%$ in 2010 to $66 \%$ in $2019 .{ }^{18} \mathrm{Nev}$ ertheless, nearly one third of the world's population, or 2.6 billion people, continue primarily using polluting fuels and technologies for cooking, an estimate that has remained roughly unchanged since 1990 , given population growth. ${ }^{18}$ Under current and planned policies, 2.4 billion people are expected to remain in this situation by $2030 .^{18}$

Even households with access to clean fuels and technologies often continue to use polluting fuels in tandem, a practice known as "stove stacking." ${ }^{19}$ People might use different fuels or stoves for different cooking tasks, or might use clean fuels for cooking but polluting fuels for heating or lighting. Secondary use of polluting fuels among those who primarily use clean fuel means continued emissions of household air pollution that harm health and the climate. Secondary use of clean fuels among those who primarily use polluting fuels is an important indicator of gains in access to clean household energy. These distinctions between access to, and exclusive use of, clean fuels are critical; increasing availability of clean 


\begin{tabular}{|c|c|c|}
\hline & Previnuclucollected & Added to latect vercion \\
\hline \multicolumn{3}{|l|}{ Cooking: } \\
\hline Primary cooking fuel & $x$ & $x$ \\
\hline Cooking location & $x$ & $x$ \\
\hline Primary cookstove & & $x$ \\
\hline Cookstove chimney or hood & & $x$ \\
\hline Time spent collecting fuel ${ }^{*}$ & & $(\mathrm{X}) \dagger$ \\
\hline Time spent cooking ${ }^{*}$ & & $\neq$ \\
\hline \multicolumn{3}{|l|}{ Primary fuel collector* } \\
\hline \multicolumn{3}{|l|}{ Primary cook* } \\
\hline \multicolumn{3}{|l|}{ Injuries from fuel collection* } \\
\hline \multicolumn{3}{|l|}{ Heating: } \\
\hline Primary heating device & & $x$ \\
\hline Primary heating fuel & & $x$ \\
\hline Heater chimney or hood & & $x$ \\
\hline \multicolumn{3}{|l|}{ Other heating fuels } \\
\hline \multicolumn{3}{|l|}{ Other heating devices } \\
\hline \multicolumn{3}{|l|}{ Months per year with heat use } \\
\hline \multicolumn{3}{|l|}{ Injuries from heating devices } \\
\hline \multicolumn{3}{|l|}{ Lighting: } \\
\hline Primary lighting source & & $x$ \\
\hline \multicolumn{3}{|l|}{ Other lighting sources } \\
\hline \multicolumn{3}{|l|}{ Injuries from lighting sources } \\
\hline \multicolumn{3}{|c|}{$\begin{array}{l}\text { *Indicators for monitoring gendered health and livelihood impacts of household energy use. } \\
\text { the child labour section of the MICS household questionnaire (MICS5) included a question on the combined time spent } \\
\text { collecting water and wood by children. MICS6 added a questionnaire for children aged 5-17, which includes questions for } \\
\text { one randomly selected child from each household on time spent collecting firewood for household use and whether the } \\
\text { child helps with cooking. The sex of the child is also recorded in the MICS6 household questionnaire. } \\
\text { fThe MICS6 questionnaire for children aged } 5-17 \text { asks about total time spent on various domestic activities (including } \\
\text { cooking and other tasks); time spent specifically on cooking is not recorded. }\end{array}$} \\
\hline
\end{tabular}

fuels denotes progress, but the transition to clean household energy must be nearly exclusive (with polluting stoves almost completely abandoned) to achieve maximum benefits for health and climate. ${ }^{20}$

\section{Better national data needed}

Assessing progress toward the use of clean household energy, and how this progress (or lack thereof) differentially affects men, women, boys, and girls, require more indepth, national data. Therefore, WHO and the World Bank developed a set of core questions for household energy use, designed to be integrated into national surveys. It includes essential questions needed to track progress toward SDG 7 and recommended questions on the gendered health and livelihood impacts of household energy use. ${ }^{21}$ These recently launched core questions have been steadily advancing national level household energy data. The latest versions of MICS and DHS (MICS6 and DHS8) have incorporated some of these core questions as they now ask about the main fuels and technologies used for cooking, heating, and lighting, which will enhance our understanding of household energy use. ${ }^{12} 13$

As the custodial agency for reporting on SDG indicator 7.1 .2 (proportion of population with primary reliance on clean fuels and technology), ${ }^{17}$ WHO uses information on primary cooking fuel and technology to calculate the indicator. Although the indicator goes beyond a focus on cooking, primary cooking fuels and technologies are the only widely available nationally representative data. The new data that are now being collected in national surveys such as MICS and DHS will enable WHO to classify households as primarily reliant on clean energy only if they use clean fuels and technologies for cooking, heating, and lighting. This change will enable more accurate monitoring of progress toward SDG 7.

Despite these advances, important data gaps remain, impeding a nuanced understanding of exposures to, and effects of, household air pollution and how they are proportionally distributed, especially by sex. Firstly, when the surveys attempt to identify only the main type of fuel and device used for cooking, heating, and lighting in each household, they fail to account for increasing access to clean fuels that are used secondarily, or for continued release of household air pollution from secondary use of polluting fuels. Therefore, current data do not indicate the extent to which stacking with clean and polluting fuels continues, or whether stacking can be eliminated through, for example, sufficient financial support.

Secondly, the questions focus on the household, not the individual, thus failing to identify roles of household members, including who is the primary collector and user of the fuels and technologies and, consequently, who bears the greatest burden. Although MICS6 has integrated a questionnaire for children aged 5-17 that includes questions on time spent collecting firewood, participation in household cooking, and time spent completing domestic tasks (including cooking), this information is collected for only one randomly selected child in each household (not other children, adult women, or other household members). ${ }^{12}$

Additional data are essential to obtain a more complete understanding of the gendered effects of household energy use and household air pollution, and to help inform national and international investment and policy decisions about global public health. At a minimum, additional questions are needed on, firstly, all fuels and technologies used for cooking, heating, and lighting; secondly, who in the household is responsible for collecting and using the fuel; and thirdly, how much time each household member spends on these tasks. Other questions not listed here, such as those related to decision making dynamics and household energy use behaviours, would provide further detail but would need to be weighed against the drawbacks of prolonged surveys to assess importance versus feasibility.

Table 1 depicts the questions about household energy that were previously included in routine national surveys, the questions that are now being administered in MICS6 and DHS8 and are essential for reporting on SDG indicator 7.1.2, and the recommended indicators from WHO and the World Bank's core questions for inclusion in national surveys. Questions that, if asked, would enable a better understanding of the gendered health and livelihood impacts of household energy use are marked in the table.

These additional data on all fuels and technologies used in households and who uses them would also allow for a more nuanced understanding of the linkages between SDGs, especially SDG 7 (ensure access to clean energy), SDG 5 (achieve gender equality), and SDG 13 (combat climate change). ${ }^{17}$ For example, data on responsibilities for cooking and fuel collection and how these change with 
transitions to clean energy can enable monitoring of progress toward shared responsibilities for domestic work, such as men assuming more responsibility for collecting and cooking with clean fuels (SDG target 5.4); track the expected impact of clean household energy policies on gender equality (SDG target 5c); inform the association between household energy and violence against women, which can occur when women collect fuel alone, especially in populations affected by crisis ${ }^{22}$ (SDG target 5.2); and indicate women's progress toward accessing household energy resources to support their empowerment (SDG target 5b). Furthermore, enhanced monitoring might help to quantify the effect of household energy use on the climate, which could strengthen the case for the use of clean household energy to combat climate change.

The recommended core questions related to gendered impacts and secondary fuel use are not currently included in standard national surveys (that is, DHS and MICS), but are critical to advance our understanding of the association between household energy use, sex, and gender. Governments can and should request agencies to add these questions to national surveys to better characterise gendered impacts and inform investment and policy decisions on household energy. Such questions will also enable more comprehensive tracking of progress towards multiple SDGs. Systematic administration of these questions nationally will enhance their universal value, resulting in data that can be shared and compared over time, across different studies, and across countries and regions.

Critically, expanded data that describe the gendered dimensions of household energy use can inform more effective interventions to deal with household air pollution. As women are the likely primary users of household energy, their roles, needs, capacities, perceptions, and power within households must be considered in the design of any intervention. More explicit consideration of gender, informed by data, can enable better tailoring of products, communication campaigns, and implementation approaches, which will ultimately ensure that households not only acquire cleaner devices for cooking, heating, and lighting but also use those devices correctly and exclusively. ${ }^{23}$ Increased reliance on clean household energy might, in turn, build resilience to the effects of climate change-for example, by making households less vulnerable to the scarcity of fuelwood.

\section{Ways forward}

Although great strides have been made in generating more useful and reliable data on household energy use and air pollution over the past three decades, considerable gaps in knowledge remain. Filling these gaps depends, in part, on harnessing and harmonising the true potential of household energy data. This aim can be achieved through global systematic surveillance measures, such as the WHO and World Bank core questions on household energy use, and by dedicating resources to collecting these high priority data. Numbers are often called upon to "speak for" the needs and priorities of populations, ${ }^{24}$ but without higher quality surveillance data, identifying and advancing effective solutions to the household air pollution problem remain hindered. A commitment to quality improvement and consideration of gender in the collection of data is critical to generating the evidence needed to increase access to, and use of, clean household energy and, ultimately, improving health, enhancing livelihoods, and slowing climate change. Although this is not a trivial challenge, we can overcome it one survey at a time, tweaking the old public health adage "what gets measured, gets done" to "what gets measured well, gets done well."25

We thank Avni Amin, Diarmid Campbell-Lendrum, and Paul Safar for their help in producing this article.

Contributors and sources: HA-R and JJL provided air quality and health expertise. EVP and ZH provided climate change, health, and gender expertise. EVP conceived the paper. EVP and JJL guided the scope and content of the manuscript. ZH and KNW conducted research and prepared the full draft of the manuscript, incorporating revisions and comments from all authors. All the authors critically reviewed, revised, and contributed to the manuscript. $\mathrm{ZH}$ and KNW contributed equally and are joint first authors. $\mathrm{HA}-\mathrm{R}$ is the guarantor.

Competing interests: We have read and understood BMJ policy on declaration of interests and have no interests to declare.

Provenance and peer review: Commissioned; externally peer reviewed.

This article is part of a series commissioned by The $B M J$, based on an idea from the United Nations University-International Institute for Global Health (UNU-\|GH) and the World Health Organization, to mark the 25th anniversary of the adoption of the 1995 Beijing Declaration and platform for action. The $B M$ / retained full editorial control over external peer review, editing, and decision to publish. Open access fees for this collection were paid by the United Nations University-International Institute for Global Health and WHO. The authors alone are responsible for the views expressed, and they do not necessarily represent the views, decisions or policies of UNU, UNU-IIGH, or WHO.

Zeenah Haddad, consultant

Kendra N Williams, consultant

Jessica J Lewis, technical officer, air quality and health
Elena Villalobos Prats, technical officer, climate change and health

Heather Adair-Rohani, technical officer, air quality and health

Department for Environment, Climate Change, and Health, World Health Organization, Geneva, Switzerland

Correspondence to: HAdair-Rohani

adairrohanih@who.int

\section{(c) $($ ) (8)}

This is an Open Access article distributed under the terms of the Creative Commons Attribution IGO License (https://creativecommons.org/licenses/ by-nc/3.0/igo/), which permits use, distribution, and reproduction for non-commercial purposes in any medium, provided the original work is properly cited.

\section{Check for updates}

1 World Health Organization. The global health observatory: household air pollution. 2018. https:// www.who.int/data/gho/data/themes/topics/topicdetails/GHO/household-air-pollution

2 Bennitt FB, Wozniak SS, Causey K, Burkart K, Brauer M. Estimating disease burden attributable to household air pollution: new methods within the global burden of disease study. Lancet Glob Health 2021:9:S18. doi:10.1016/S2214 $109 \times(21) 00126-1$

3 Goldemberg J, Martinez-Gomez J, Sagar A, Smith KR. Environ Res Lett 2018;13:030201. doi:10.1088/1748-9326/aaa49d.

4 Bailis R, Drigo R, Ghilardi A, Masera O. The carbon footprint of traditional woodfuels. Nat Clim Chang 2015;5:266-72. doi:10.1038/nclimate2491.

World Health Organization. Burning opportunity: clean household energy for health, sustainable development, and wellbeing of women and

children. 2016. https://apps.who.int/iris/ handle/10665/204717

6 Shankar A, Johnson M, Kay E, et al. Maximizing the benefits of improved cookstoves: moving from acquisition to correct and consistent use. Glob Health Sci Pract 2014:2:268-74. doi:10.9745/ GHSP-D-14-00060

7 Krishnapriya PP, Chandrasekaran M, Jeuland M. Pattanayak SK. Do improved cookstoves save time and improve gender outcomes? Evidence from six developing countries. Energy Econ 2021;102:105456. doi:10.1016/j. eneco.2021.105456.

8 GBD 2019 Risk Factors Collaborators. Global burden of 87 risk factors in 204 countries and territories, 1990-2019: a systematic analysis for the Global Burden of Disease Study 2019. Lancet 2020;396:1223-49. doi:10.1016/S01406736(20)30752-2

9 Institute for Health Metrics and Evaluation (IHME). GBD compare data visualization. 2020. http:// Vizhub.healthdata.org/gbd-compare.

10 Pope D, Bruce N, Dherani M, Jagoe K, Rehfuess E. Real-life effectiveness of 'improved' stoves and clean fuels in reducing $\mathrm{PM}_{25}$ and $\mathrm{CO}$ : systematic review and meta-analysis. Environ Int 2017;101:7-18. doi:10.1016/j.envint.2017.01.012

11 Quansah R, Semple S, Ochieng CA, et al. Effectiveness of interventions to reduce household air pollution and/or improve health in homes using solid fuel in low-and-middle income countries: a systematic review and meta-analysis. Environ Int 2017:103:73-90. doi:10.1016/. envint.2017.03.010

12 Unicef. Multiple indicator cluster surveys (MICS) 2021. https://mics.unicef.org L

13 USAID. The demographic and health surveys (DHS) program. 2020. https://dhsprogram.com/ 
14 Smith KR, Bruce N, Balakrishnan K, et al, HAP CRA Risk Expert Group. Millions of dead: how do we know and what does it mean? Methods used in the comparative risk assessment of household air pollution. Annu Rev Public Health 2014;35:185-206. doi:10.1146/annurev-publhealth-032013-182356

15 World Health Organization. WHO indoor air quality guidelines: household fuel combustion. 2014. https://www.who.int/publications/i/ item/978924154888

16 Quinn A, Bruce N, Puzzolo E, et al. An analysis of efforts to scale up clean household energy for cooking around the world. Energy Sustain Dev 2018;46:1-10. doi:10.1016/j.esd.2018.06.011

17 United Nations. Transforming our world: the 2030 agenda for sustainable development. 2015. https:// sdgs.un.org/publications/transforming-our-world 2030-agenda-sustainable-development-17981

18 IEA, IRENA, UNSD, World Bank, WHO. Tracking SDG7: the energy progress report. 2021. Downloads | Tracking SDG 7 (esmap.org)
19 Shankar AV, Quinn A, Dickinson KL, et al. Everybody stacks: lessons from household energy case studies to inform design principles for clean energy transitions. Energy Policy 2020;141:111468. doi:10.1016/j.enpol.2020.111468

20 Johnson MA, Chiang RA. Quantitative guidance for stove usage and performance to achieve health and environmental targets. Environ Health Perspect 2015;123:820-6. doi:10.1289/ ehp.1408681

21 WHO. Core questions on household energy use. 2019https://www.who.int/tools/core-questions-forhousehold-energy-use.

22 Clean Cooking Alliance. Statistical snapshot: access to improved cookstoves and fuels and its impact on women's safety in crises. 2015; https://www. cleancookingalliance.org/binary-data/RESOURCE/ file/000/000/353-1.pdf.

23 Evans WD, Johnson M, Jagoe K, et al. Evaluation of behavior change communication campaigns to promote modern cookstove purchase and use in lower middle income countries. Int I Environ Res Public Health 2017;15:11. doi:10.3390/ ijerph15010011

24 Tichenor M, Sridhar D. Metric partnerships: global burden of disease estimates within the World Bank, the World Health Organisation and the Institute for Health Metrics and Evaluation. Wellcome Open Res 2019;4:35. doi:10.12688/ wellcomeopenres.15011.1

25 Nsubuga P, White ME, Thacker SB, et al. Public health surveillance: a tool for targeting and monitoring interventions (chapter 53). In: Jamison D, Breman J, Measham AR, et al, eds. Disease control priorities in developing countries. 2nd ed. Oxford University Press, International Bank for Reconstruction and Development, World Bank, 2006. https://www.ncbi. nlm.nih.gov/books/NBK11770.

Cite this as: $B M / 2021 ; 375: \mathrm{n} 2273$

http://dx.doi.org/10.1136/bmj.n2273 